\title{
Wear Resistance of Gold Alloys for Coinage
}

\author{
AN EARLY EXAMPLE OF CONTRACT RESEARCH
}

\section{J. C. Chaston}

Contract research is sometimes looked upon as a fashion of the seventies, but it can in truth boast a long and distinguished ancestry; a research contract for investigating the metallurgy of gold alloys was placed nearly two hundred years ago by a Committee of the Privy Council of the United Kingdom.

Towards the end of the eighteenth century concern was expressed that the economy of the realm was suffering great losses through the wear of the gold coinage. On February 10th, 1798, the Privy Council appointed a Committee "to take into consideration the state of the coins of this kingdom, and the present establishment and constitution of His Majesty's Mint".

The Committee was indeed a formidable one. The president was the Earl of Liverpool, and its members included, among others, the Lord High Chancellor, all of His Majesty's Principal Secretaries of State, the Master General of the Ordnance, the Chancellor of the Exchequer, two Lord Chief Justices, the Speaker of the House of Commons, the Master of the Rolls, and-for good measure-Sir Joseph Banks, the President of the Royal Society. Their deliberations have not been recorded but within a very short time "having among other circumstances remarked the considerable loss which the gold coin appeared to have sustained by wear within certain periods and being desirous to ascertain whether this loss was occasioned by any defect, either in the quality of the standard gold or in the figure or impression of the coins" the Committee appointed Charles Hatchett, Esq., F.R.S., and Henry Cavendish, Esq., F.R.S., to examine "by such experiments as should be deemed requisite, whether any of these defects really existed".

\section{Charles Hatchett \\ $1765-1847$}

Born in London the son of a wealthy coachmaker, Hatchett preferred chemistry to his father's business, and acquired an international reputation as a mineral analyst. He was elected to the Royal Society in 1797 and a year later was asked by the Beitish Government to undertake, together with Cavendish, an investigation into the wear resistance of gold alloys for use in coinage. On his father's death he inherited a fortune and at the age of forty ceased to play a part in scientific matters
Hatchett is best remembered as the discoverer in 1801 of the metallic element niobium in a sample of mineral found by the first Governor of Connecticut, John Winthrop the Younger, in a stream near New London, and sent by his grandson to Sir Hans Sloane in London. Hatchett called it columbium and it may be thought a pity that his choice has not been retained. Berzeluis wrote vividly in his diary during a visit to London in 1812 that:

"Hatchett himself is a very agreeable man of about forty to forty-five years [he was then 47]. His father was a rich coachmaker and the son, although a famous chemist at the time of his father's death, has continued to carry on the business. He is in very good circumstances, and lives in Roehampton on a little estate built in a fine Italian style and excellently maintained. Close by his Italian villa he has a very well equipped laboratory, but for a long time he has not worked."

His first research contract may well have been his last.

Cavendish, one of the great eccentrics, and in his later years one of the wealthiest men in the country, was also an unrivalled experimenter, and as will be

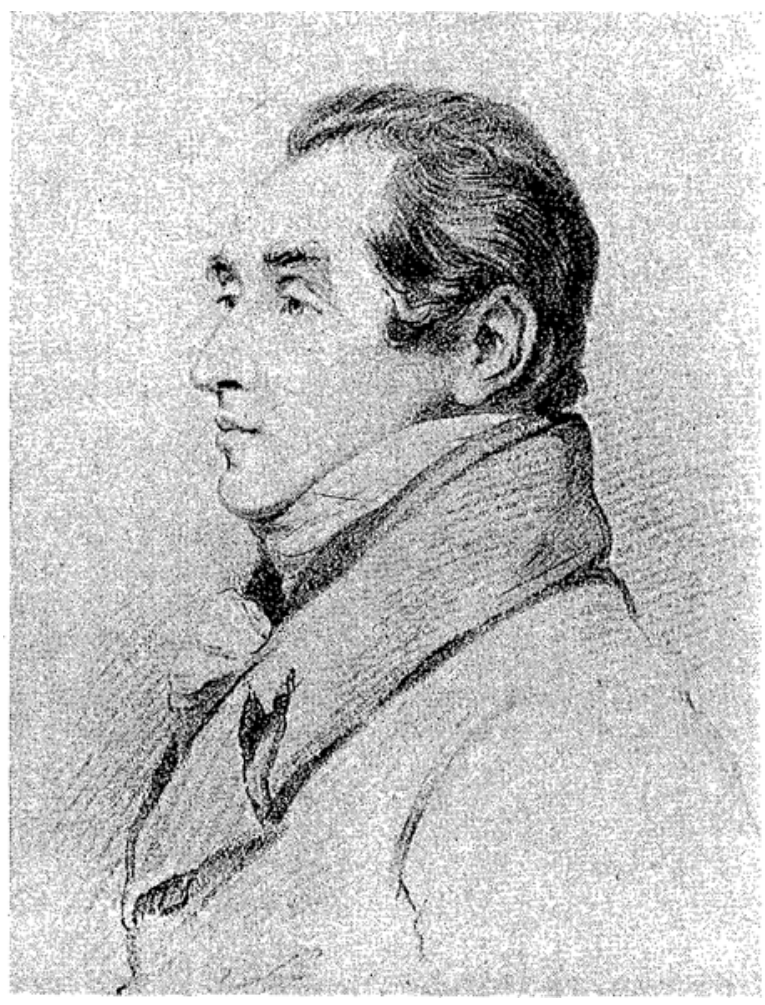




\section{Henry Cavendish \\ $1731-1810$}

One of the greatest scientists of all time Cavendish lived the life of a recluse and invariably wore the dress of a by-gone age. This is the only portrait of him, made surdinner of the Royal Society Club and now preserved in the British Museum. In Hatchett's report to the Privy Council he wrote: "At the request of $\mathrm{Mr}$ Cavendish I have written the following account, but I should be highly unjust and ungrateful to that gentleman did $I$ truly belongs to him of any merit. which these experiments may he found to possess; for at all times I was favoured with his valuable advice, and the machines to produce friction, as reptitiously by William Alexander during a not publicly acknowledge how great a portion well as the dies, were entirely contrived by him"

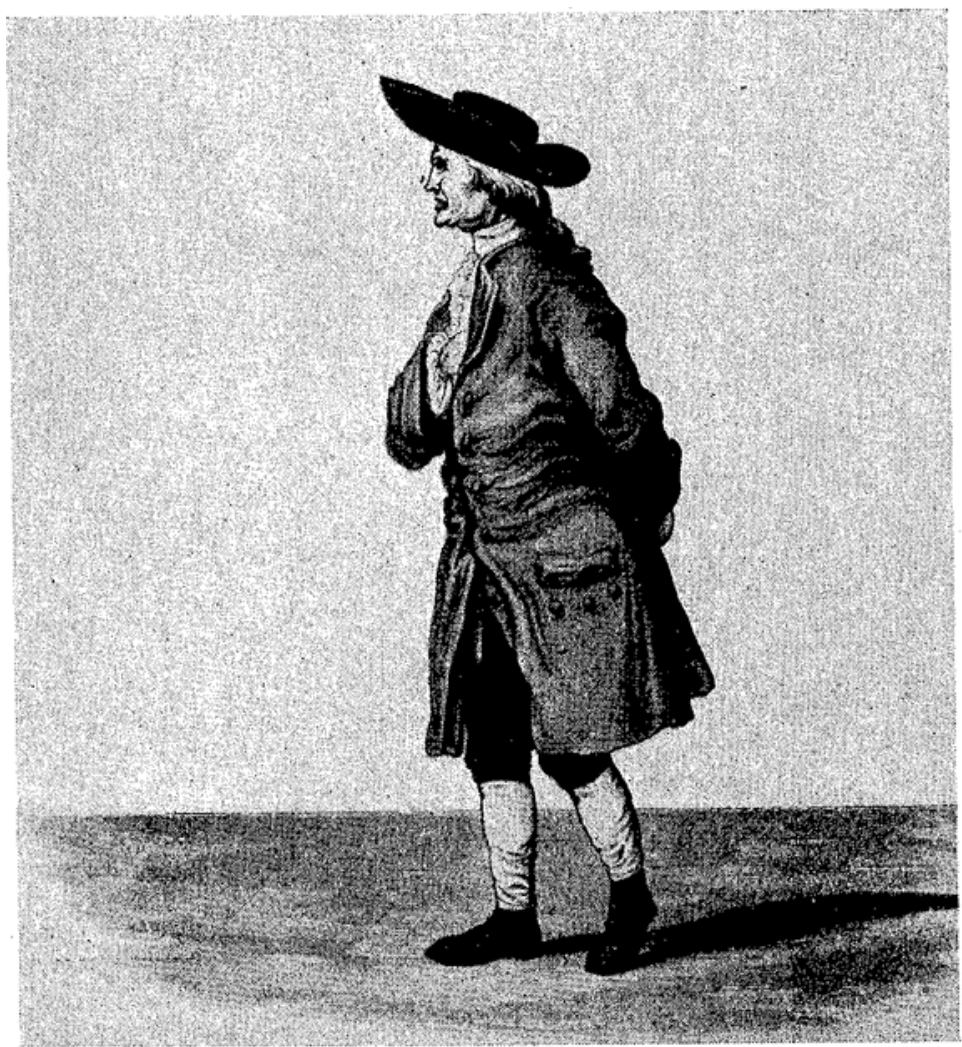

apparent he displayed all his skills in this undertaking. His laboratory at the time was probably his house in Bloomsbury. Nothing is known of the conditions of the research contract, but both men applied themselves with diligence to the task and the substance of their report was incorporated by Hatchett in a paper read before the Royal Society on 13th January 1803 and published in the Philosophical Transactions (1803, 93, pp. 43-194). Cavendish, characteristically, was content to leave it to Hatchett to present the conclusions of their separate efforts.

It is interesting to compare the approach adopted to an essentially technological problem in 1798 with the one which would be chosen today. Two questions, the investigators thought, were to be principally considered:

(1) Whether a very soft and ductile gold or an alloy made as hard as compatible with the process of coining would best resist the wear to which coinage was subjected.

(2) Whether a smooth-faced coin would wear better than one heavily embossed.

It does not seem to have entered their minds to seek evidence of the alleged excessive wear which was the subject of their enquiry, or even to seek to relate wear with the year of issue of sample batches of coins taken from circulation. In that age mankind may be said to have been statistically oblivious.

Hatchett, with no precedents to guide him, evidently thought it prudent to start his report with a compliment to his sponsors. After pointing out that the high cost of gold "had hitherto prevented private ment" he went on to emphasise that "this subject of investigation, although so important to political economy and to science, does not appear to have been noticed by any European Government until the Right Honourable and enlightened Members of the above-mentioned Committee proposed the enquiry and furnished the requisite means for making the experiments".

\section{Thirteen Binary Alloys}

More than half of the long report consists of a detailed description of the production of thirteen binary 22-carat gold alloys. Acknowledgement is made to the Deputy Master of the Mint and others (especial mention is made of $\mathrm{Mr}$ Bingley, His Majesty's Assay Officer) for "the ready assistance and polite attention received during the long series of experiments made at the Mint".

The alloys were judged mainly by their response to the action of hammering and, when malleable, by their ease of rolling, and some of the observations much time was spent in examining the behaviour of tin-gold alloys, which were much more easily worked than expected. Tin additions had previously been generally considered to be injurious to the ductility of gold alloys. individuals from ascertaining these facts by experioccasioned considerable surprise. In particular, 


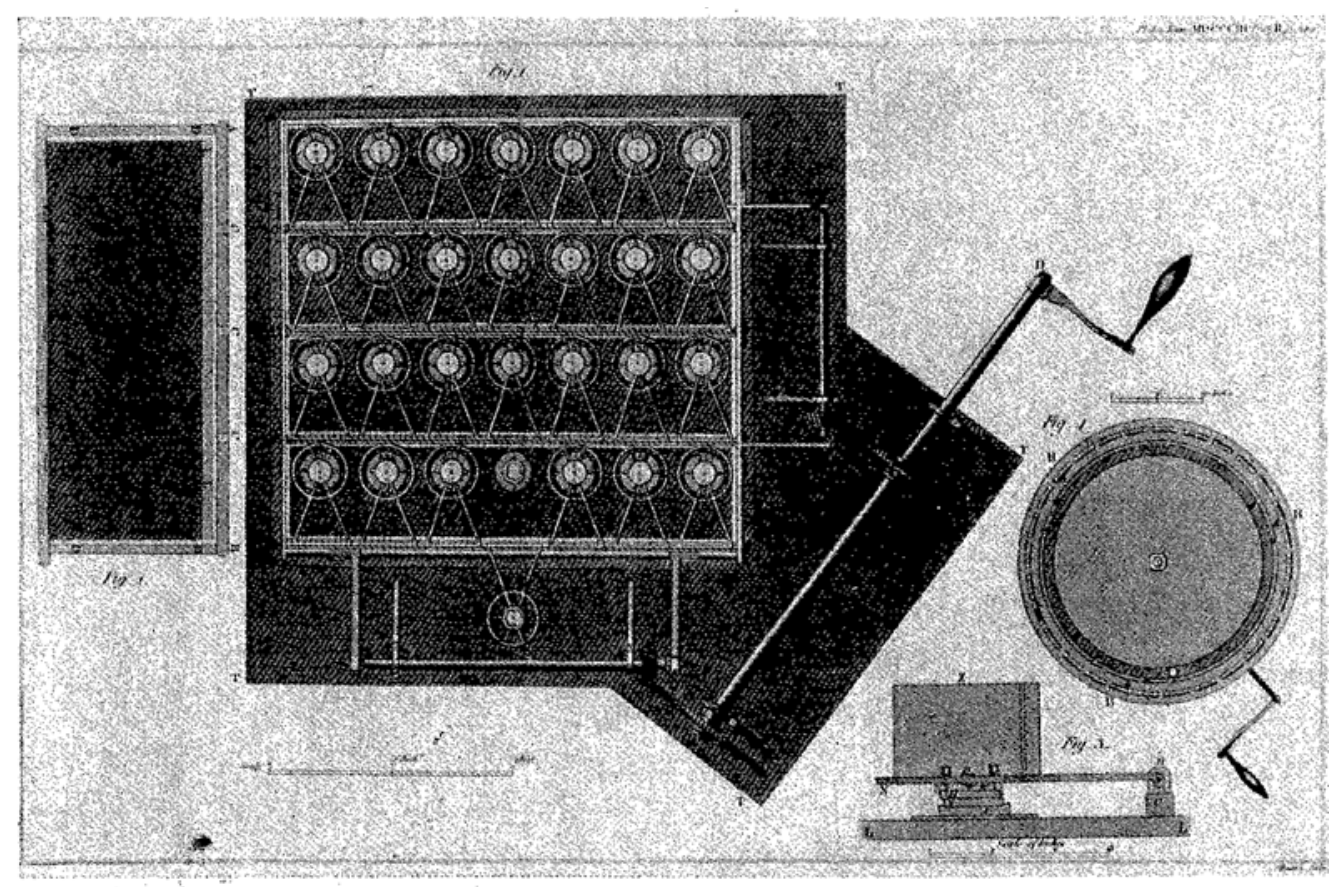

The wear testing machine designed by Cavendish and constructed for him by the well-known instrument maker John Cuthbertson. It was arranged to hold 28 gold coin blanks in the lower frame, while a further 28 in the upper were pressed downwards by weights and caused to rub across the lower ones by turning the handle. The appreciation of the complex nature of wear shown by Cavendish was well ahead of his time and could have been studied with advantage by later investigators

The general conclusion reached was that individual additions of an amount equal to 2 carats $(1 / 12)$ of a second metal to gold impaired malleability in the following decreasing order:
(1) Bismuth, Lead or Antimony
(2) Arsenic
(3) Zinc
(4) Cobalt
(5) Manganese
(6) Nickel
(7) Tin
(8) Iron
(9) Platinum
(10) Copper
(11) Silver

The surprisingly discerning note is added that the position of platinum in the table may have been affected by the presence of iron as an impurity. It was thought that platinum might have had even less influence on malleability if it had been pure. It was a good point, but in fact iron in the quantities involved has little effect on the mechanical properties of 22 carat gold-platinum alloys. On the other hand, Hatchett did not apparently appreciate how impure was the manganese he used.

For good measure, Hatchett planned to include in his report values of the specific gravity of all the alloys, but the results of his measurements opened up complications which he had not envisaged. He was soon led to the conclusion that "in general, the specific gravity of gold alloys alloyed with different metals is very different to what it ought to be according to calculation"; and moreover that it was "subject to many various complications".

$\mathrm{He}$ was particularly concerned with the possible cause of differences between determinations made on various parts of the same casting. Primarily, he thought it might be inferred that "when cast, the greatest density prevails in the lower part of the column or in that which suffers the greatest pressures from the superincumbent liquid". He listed four possible causes of density variation:

"(a) Imperfections in the interior of the mass, which are produced during the processes of melting and casting.

"(b) The difference in density in parts of the same mass, resulting from the quality and quantity of the metal, from the nature of the mould, from the more or less vertical position of it, and from the height of the column or bar of metal which is cast.

" $(c)$ The unequal distribution of the metal, or metals, employed as an alloy, throughout the mass intended to be alloyed.

"(d) The peculiar effects which certain metals produce, when used singly or conjointly as alloys, which are very different from the results of calculation." [A footnote remarks that "the effects of compound alloys are, in general, very different from each metal separately considered", and hints that some alloys may be real chemical combinations.]

"(e) Heat, whether produced by friction or excited in any other manner." 
This list, conscientiously compiled by a careful observer and an outstanding manipulator as a chemical analyst, vividly illuminates the difficulties stemming from the lack of any real understanding of the processes of solidification or of the mechanism of alloying. Nearly a hundred years were to pass before the pioneer work of such men as RobertsAusten, Osmond, and Roozeboom was to provide a solid theoretical basis on which to build an explanation of these curious effects. Nobody even suspected the possibility that dissolved gases might be evolved or, even more, interact at the moment of solidification of a metal or alloy. Of Hatchett's conclusions, the reference to imperfections in the castings is reasonable enough; the causes of "unequal distribution" by normal and inverse segregation were to be a matter of controversy for many decades, and "combinational effects" might well be expected. Only the reference to "heat effects" was illogical, and this may be excused in one caught up in such an apparently irrational observational jungle. Few papers so well illustrate the difficulties besetting the worker in metals at the turn of the nineteenth century.

\section{Design of the Wear Testing Machine}

In the second part of the paper, the measurement of wear resistance was investigated completely and thoroughly by Cavendish, who designed an ingenious testing machine (constructed for him by $\mathrm{Mr}$ Cuthbertson of Poland Street, London) and who also:

(a) observed the wear of batches of 200 pieces after they had been enclosed for various periods in a rotating wooden box; and

(b) measured the wear of pieces pressed against the rim of a flat horizontal wheel by weights. "That part of the wheel against which the pieces rubbed was sprinkled or coated with some kind of powder [such as iron filings]".

Mr Cuthbertson "had the care of these machines during the experiments which were made at his house". Cavendish's wear machine, illustrated here, was arranged to hold 28 pieces of coin in a lower frame, and another 28 coins, attached to a second frame, were pressed downwards on the first by weights. The illustration clearly shows how each pair of coins was loaded by an individual weight. It was at first intended that the lower frame should remain fixed and that the upper should be moved back and forth with a travel of about $3 / 8$ th inch. The movement was achieved by turning the driving wheel manually. It was found, however, that little furrows or gullies were very rapidly worn on the faces of the coins, apparently by particles of metal which had been abraded and subsequently accumulated on the faces of the lower coins. It was therefore decided to move both upper and lower frames at different rates-the top oscillating six times and the lower five times for every revolution of the counter. This arrangement very much reduced but did not completely eliminate grooving. Tests were made using both plain coin blanks and discs embossed with a standard pattern, and included couples of like and unlike metals. The labour involved in the manual operation of the machines must have been great: we are not told who turned the handle. The degree of wear was measured in terms of the loss of weight of the coins. In a typical experiment the wear of 12 pieces after 573,380 cycles of operation under a load of $3 \frac{1}{2} \mathrm{lb}$ (recognised by Cavendish as being too heavy to be really representative) amounted to 8.60 grains.

Coins with embossed surfaces were found to wear faster under every circumstance than those which were smooth and flat, but the difference was not great. In the barrel, for instance, after 71,720 revolutions 200 unstamped pieces weighing 13,679.4 grains lost 198.7 grains whereas 200 stamped ones weighing 13,701.3 grains lost 199.3 grains. Embossed coins, it was noted, often appeared worn, with the pattern obliterated without any appreciable loss of weight, simply "by a depression of the prominent parts which have been forced into the mass and become reduced to a level with the ground of the coin".

\section{The Nature of Wear}

Finally it is worth noting that Cavendish observed metal transfer in some instances. Standard silver coins, for instance, were often coated with copper or gold from coins of other denominations. Cavendish in fact appreciated very clearly the complex nature of wear, and in particular that rubbing wear was not the same as the wear caused by the grinding action of abrasive particles broken from a hard and brittle material. Thus he made no attempt simply to place the various alloys in order of a generalised "wear resistance". He stated his main conclusions as follows:

"(1) When equal' friction, assisted by a moderate pressure, takes place between pieces of coin which in each series are of a similar quality their abrasion is most commonly produced in an inverse ratio to the degree of ductility [i.e. the softest wore the least].

"(2) The contrary effect happens when pieces of different quality rub against each other; for then the more ductile metal is worn by that which is hardest.

"(3) Earthy products and metallic filings produce similar effects and tend to wear the different kinds of gold in proportion to the 'respective degrees of ductility' [i.e. the softest alloys were the most worn]." 
The grasp shown by Cavendish of the complex nature of wear was masterly; it could have been studied with advantage by investigators a century later.

\section{Conclusions of the Final Report}

Thus it was reported back to the Committee of the Privy Council that there was nothing to be gained by substituting a harder or a softer coinage alloy for the standard 22 carat gold, though Hatchett did not say it in so many words. His conclusions are too verbose for full quotation, but an extract will give their substance.

"The extraordinary loss," he wrote "which gold coin of this kingdom is stated to have sustained within a certain limited time cannot, with even a shadow of probability, be attributed to an important defect in the composition or quality of the standard gold: and all that can be said upon the subject is, that some portion of this loss may have been caused by the rough impression and milled edge now in use, by which each piece of coin acts, and is acted upon by others, in the manner of a file. ... When a number of guineas, rather loosely packed, have been long shaken together by the motion of a coach or other carriage, the effects of friction are observed chiefly to fall upon only a few of the pieces. ... Upon the whole there is every reason to believe that our gold coin suffers little by friction upon itself and the chief cause of natural and fair wear arises from particles to which they are exposed in course of circulation."

What the Committee thought is not recorded, but in May 1816, in the briefest of reports, they recommended to the Privy Council that there should be no change in the standard weight or denomination of the gold coin of the realm. Further-and they needed here no research effort to guide them-they proposed that in making silver coins the Master of the Mint should make 66 shillings instead of 62 from each troy ounce of standard silver and return 4 shillings as Brassage or Seignorage to pay for a New Mint!

Hatchett and Cavendish were not able to find a means of reducing the wear of gold coins, but the distinguished Committee was nevertheless able to propose a statesmanlike means of compensating for the inevitable losses ... simply by debasing the silver coinage.

\section{What Things may be gilded and laid on with Silver or Gold, and what not}

$I^{\mathrm{T}}$ TEM, Whereas many fraudulent Artificers, imagining to deceive the common People, do daily make Locks, Rings, Beads, Candlesticks, Harness for Girdles, Hilts, Chalices, and Sword-pomels, Powder-boxes, and Covers for Cups, of Copper and of Latten, and the same overgilt and silver like to Gold or Silver, and the same sell and put in Gage to many Men, not having full Knowledge thereof, for whole Gold and whole Silver, to the great Deceit, Loss and Hindrance of the common People, and the Wasting of Gold and Silver; (2) it is ordained and established, That no Artificer, nor other Man whatsoever he be, from henceforth shall gilt nor silver any such Locks, Rings, Beads, Candlesticks, Harness for Girdles, Chalices, Hilts, nor Pomels of Swords, Powder-boxes, nor Covers for Cups, made of Copper or Latten, upon Pain to forfeit to the Kings Cs. at every time that he shall be found guilty, and to make Satisfaction to the Party grieved for his Damages; (3) but that (Chalices always excepted) the said Artificers may work, or cause to be wrought, Ornaments for the Church of Copper and Latten, and the same gilt or silver, so that always in the Foot, or in some other Part of every such Ornament so to be made, the Copper and the Latten shall be plain, to the Intent that a Man may see whereof the Thing is made, for to eschew the Deceit aforesaid.

An Act of Parliament passed in the Year $\mathrm{I}_{4} \mathrm{O} 3$ in the Reign of King Henry IV 